\title{
Computational Comparison of Late Transition Metal (100) Surfaces for the Electrocatalytic Reduction of $\mathrm{CO}$ to $\mathrm{C}_{2}$ Species
}

\author{
Selwyn Hanselman, ${ }^{\dagger}$ Marc T. M. Koper, ${ }^{\dagger}$ and Federico Calle-Vallejo*,\#® \\ ${ }^{\dagger}$ Leiden Institute of Chemistry, Leiden University, P.O. Box 9502, 2300 RA Leiden, The Netherlands \\ \#Departament de Ciència de Materials i Química Fisica \& Institut de Química Teòrica i Computacional (IQTCUB), Universitat de \\ Barcelona, Martí i Franquès 1, 08028 Barcelona, Spain
}

Supporting Information

ABSTRACT: This Letter compares the efficiency of the conversion of $\mathrm{CO}$ to $\mathrm{C}_{2}$ species (ethanol and ethylene) on nine late transition metal (100) surfaces (Co, Ni, Cu, Rh, Pd, Ag, Ir, Pt, Au) by means of reaction onset potentials calculated using density functional theory and atomistic thermodynamics. Due to adsorption-energy scaling relations, one can model trends in limiting potentials using only two descriptors, namely $* \mathrm{C}_{2} \mathrm{O}_{2}$ and $* \mathrm{OH}$ binding energies. The resulting activity plots (i) outline the binding properties of optimal catalysts, (ii) show little dependence of the overpotential on adsorption energies, especially on the weak-binding regime, and (iii) explain why $\mathrm{Cu}(100)$ reduces $\mathrm{CO}$ to ethylene at low overpotentials. Surprisingly, CO reduction to ethanol is predicted to be thermodynamically favorable on $\operatorname{Ag}(100)$. This points toward existing experimental results and calls for detailed studies of the conditions necessary to enhance $\mathrm{CO}$ electroreduction to ethanol using Ag and its alloys.

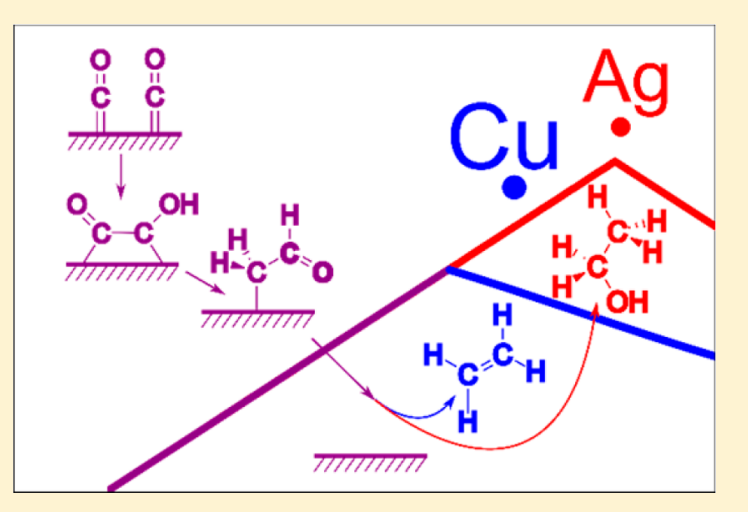

$\mathrm{O}$ ur current fossil-fuel-based economy causes twin problems: climate change caused by $\mathrm{CO}_{2}$ production and depletion of high-grade carbon compounds. ${ }^{1,2}$ Electrochemical conversion of $\mathrm{CO}_{2}$ to hydrocarbons and alcohols is a promising option for storage and use of renewable energy and an appealing synthesis resource. ${ }^{3}$ However, very few electrocatalytic materials are known that are capable of reducing $\mathrm{CO}_{2}$ beyond single carbon compounds. Compared to other (late) transition metal surfaces, $\mathrm{Cu}(100)$ shows high $\mathrm{CO}$ to $\mathrm{C}_{2}$ reduction yields at relatively low overpotentials. ${ }^{4-6}$ Previous theoretical studies confirmed the enhanced selectivity of $\mathrm{Cu}(100)$ relative to other facets of $\mathrm{Cu}$ and late transition metals. ${ }^{7,8}$ With $\mathrm{CO}$ identified as a key intermediate for $\mathrm{CO}_{2}$ reduction to hydrocarbons on transition metals, ${ }^{9-11}$ recent papers propose that on $\mathrm{Cu}(100)$ a low-overpotential pathway exists for the $\mathrm{CO}$ reduction reaction (CORR) involving the formation of an adsorbed $\mathrm{CO}$ dimer as the carbon-carbon coupling step (Figure 1). ${ }^{6,10,12,13}$

The key role of the CO dimer is supported by DFT calculations and spectroscopic observation of its immediate successor, the protonated dimer $\mathrm{COCOH} .{ }^{13-15}$ Other authors consider that $\mathrm{C}_{2} \mathrm{O}_{2}$ hydrogenation leads to $\mathrm{COCHO}{ }^{16,17} \mathrm{We}$ focus on $\mathrm{COCOH}$ because it is more stable in water than $\mathrm{COCHO}$, as $-\mathrm{OH}$ groups form hydrogen bonds with water whereas - $\mathrm{CHO}$ groups do not. Moreover, Pérez-Gallent et al. observed two specific vibrational frequencies assigned to $\mathrm{COCOH}$ through DFT calculations. ${ }^{14} \mathrm{COCHO}$ exhibited only one such frequency. ${ }^{14}$ In addition, experiments have shown that electroreduction of molecules with - $\mathrm{CHO}$ groups, namely acetaldehyde $\left(\mathrm{CH}_{3} \mathrm{CHO}\right)$, glyoxal $(\mathrm{CHOCHO})$, and glycolaldehyde $\left(\mathrm{CHOCH}_{2} \mathrm{OH}\right)$, leads to only ethanol, not to ethylene. ${ }^{12}$ In sum, we expect $\mathrm{COCOH}$ to dominate on $\mathrm{Cu}(100)$ at low overpotentials without discarding a minor alternative pathway through COCHO. As shown in Figure 1, $\mathrm{COCOH}$ is reduced to $* \mathrm{CH}_{2} \mathrm{CHO}$, the selectivity-determining intermediate. Subsequently, the pathway bifurcates into ethylene-forming and ethanol-forming routes. ${ }^{18}$

In this Letter, we compute the thermodynamics of each proton-electron transfer step on the (100) surfaces of nine late transition metals to obtain metal-specific onset potentials for CORR to ethylene and ethanol. Using these potentials, we build a plausible descriptive model to evaluate the observed differences in efficiency between transition metals, aiming at guiding the design of new electrocatalysts for CORR to $\mathrm{C}_{2}$ species.

Received: February 26, 2018

Accepted: April 3, 2018

Published: April 3, 2018 


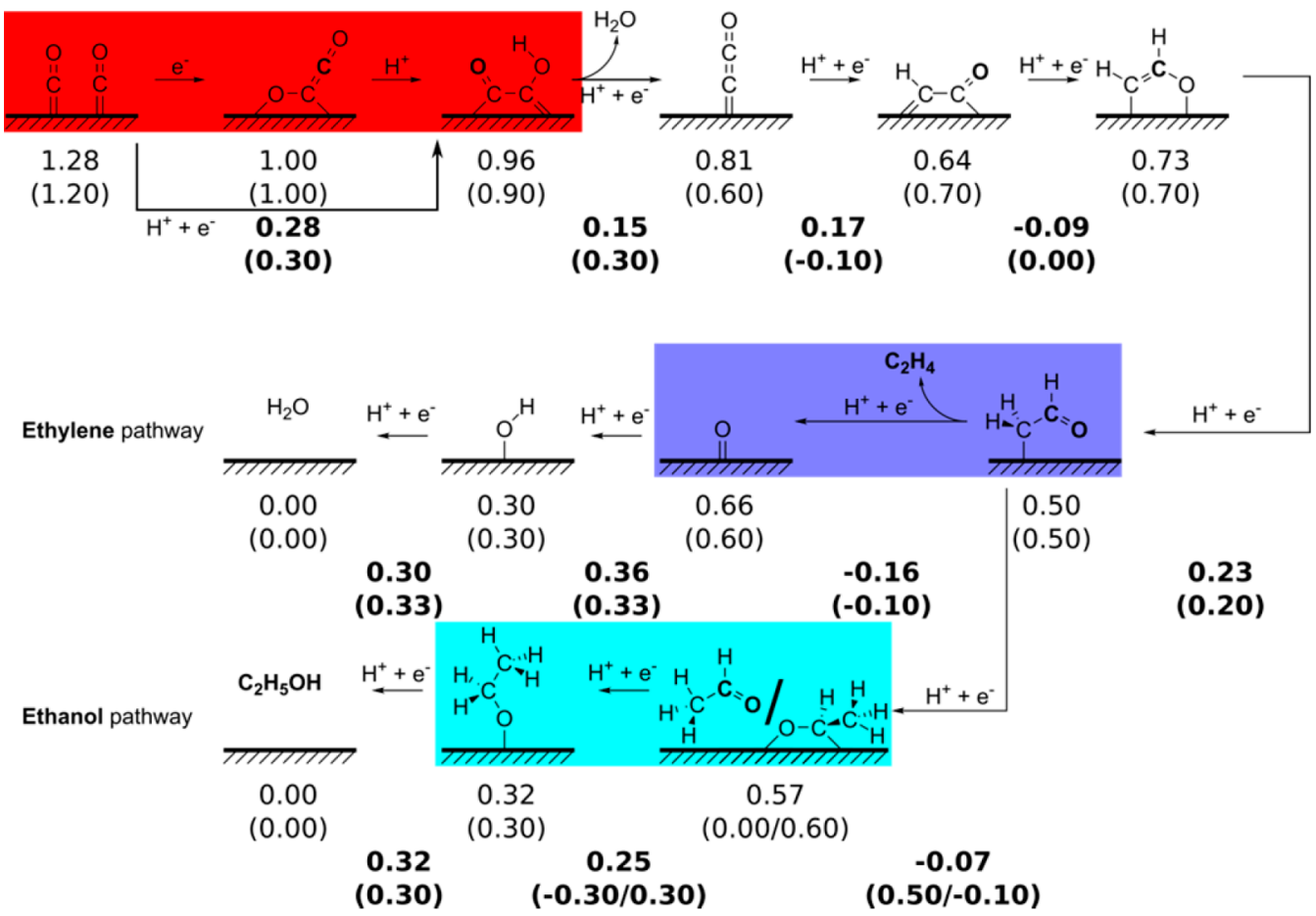

Figure 1. Proposed CORR pathways toward ethylene and ethanol. Observed adsorbate slopes are beneath configurations, while step potential slopes relative to $\Delta G_{\mathrm{C}_{2} \mathrm{O}_{2}}$ appear bold-printed under corresponding reaction arrows (numbers in parentheses are slope estimates from Figure S.1). ${ }^{13}$ Additional binding modes appear in Figure S.1. Potential-determining steps are highlighted in red (strong-binding regime), blue (weak-binding for ethylene), and cyan (weak-binding for ethanol). For $\mathrm{CH}_{3} \mathrm{CHO}$, two slopes are predicted: 0.60 based on its chemisorption and 0.00 for $\mathrm{Cu}, \mathrm{Ag}$, and $\mathrm{Au}$.

Using the computational hydrogen electrode model ${ }^{19}$ and atomistic thermodynamics, we calculated equilibrium potentials of all proton-electron transfer steps (i.e., step potentials) for each metal. The limiting potential $U_{\mathrm{L}}$ for a given metal is the most negative step potential among all steps on that metal. Besides, descriptive models of step potentials were built using scaling relations. Such linear relations arise when comparing the binding energies of similarly bound adsorbates across sets of physically similar surfaces. ${ }^{20-23}$ To facilitate the simultaneous comparison of nine metals, we assume that the mechanism in Figure 1 holds on all of them. Although this approximation simplifies the analysis, it should be used cautiously in screening studies given that pathway bifurcation is sometimes important. $^{24}$ Examples of potential pathway bifurcations are the formation of ethylene by coupling $2 * \mathrm{CH}_{2}$ generated through a $\mathrm{C}_{1}$ pathway and the aforementioned protonation of the $\mathrm{CO}$ dimer to form *COCHO instead of * $\mathrm{COCOH}$. Experimentally, the $\mathrm{CORR}$ on $\mathrm{Cu}(100)$ is $\mathrm{pH}$-independent at the onset of the reaction, ${ }^{10}$ so that $* \mathrm{CH}_{2}$ coupling has been concluded to take place only at large overpotentials. At the reaction onset, we consider that $* \mathrm{C}_{2} \mathrm{O}_{2}$ is hydrogenated to $* \mathrm{COCOH}$ instead of $* \mathrm{COCHO}$ for reasons described earlier in this Letter.

One can add and subtract scaling relations to observe trends in step potentials as a function of reference adsorbate energies. As we want to properly model the entire pathway, each intermediate should scale well $(|r|>0.90)$ with at least one descriptor. Here, all carbon-bound intermediates scale well with $\Delta G_{\mathrm{C}_{2} \mathrm{O}_{2}}$ (Figure 2), while oxygen-bound intermediates scale well with $\Delta G_{\mathrm{OH}}$ (Figure S.2).

As a first approximation, the slopes of scaling relations are calculated as the ratio between the number of surfaceadsorbate bonds of the target and descriptor adsorbates. ${ }^{21-23}$
This appears to hold in Figure 2, where we compare $\Delta G_{\text {ads }}$ slopes with respect to $\Delta G_{\mathrm{C}_{2} \mathrm{O}_{2}}$ with the ratio of average bond counts in Figure S.1. However, factors such as high covalence can cause sizable deviations from ideal slopes ${ }^{25}$ and even render them negative. ${ }^{26}$ Another factor is physisorption as scaling relations are defined for chemisorbates. Here, the slopes of the $* \mathrm{CH}_{3} \mathrm{CHO}$ vs $* \mathrm{C}_{2} \mathrm{O}_{2}$ curves deviate from our bond-count estimates because for $* \mathrm{CH}_{3} \mathrm{CHO}$ the chemisorbed configuration is unstable on weak-binding metals $(\mathrm{Cu}, \mathrm{Ag}, \mathrm{Au})$.

By combining scaling relations of the limiting steps in Figure 1 , we obtained volcano-type plots for ethylene and ethanol production, describing trends in predicted step potentials as a function of adsorption-energy descriptors. The $\Delta G_{\mathrm{C}_{2} \mathrm{O}_{2}}$-based volcanoes appear in Figure 3. Note that $\Delta G_{\mathrm{OH}}$-based volcano plots deviate from the calculated single-metal limiting potentials by more than the expected DFT functional-based error $(\sim 0.3$ $\mathrm{eV}$; see Figure S.3). ${ }^{27}$

Three limiting steps can be distilled from the limiting potentials calculated for the individual metals and volcano plots (see Figure 1): (1) for strong $\mathrm{C}_{2} \mathrm{O}_{2}$ binding, $2 * \mathrm{CO} \rightarrow$ $* \mathrm{COCOH}$ limits both $\mathrm{C}_{2}$ pathways; (2) for weak $\mathrm{C}_{2} \mathrm{O}_{2}$ binding, $* \mathrm{CH}_{2} \mathrm{CHO} \rightarrow * \mathrm{O}+\mathrm{C}_{2} \mathrm{H}_{4}$ limits the ethylene pathway; and (3) $* \mathrm{CH}_{3} \mathrm{CHO} \rightarrow * \mathrm{CH}_{3} \mathrm{CH}_{2} \mathrm{O}$ limits the ethanol pathway. A direct consequence of scaling relations and the similarity between consecutive CORR adsorbates is that the slopes in Figure 3 are never steep (see Figure 1). This makes it difficult to optimize catalysts for CORR to $\mathrm{C}_{2}$, as large changes in key adsorption energies might be necessary to observe substantial activity enhancements.

The calculated limiting potential for ethylene production on $\mathrm{Cu}(100)$ is $-0.72 \mathrm{~V}$, which is significantly less negative than the 

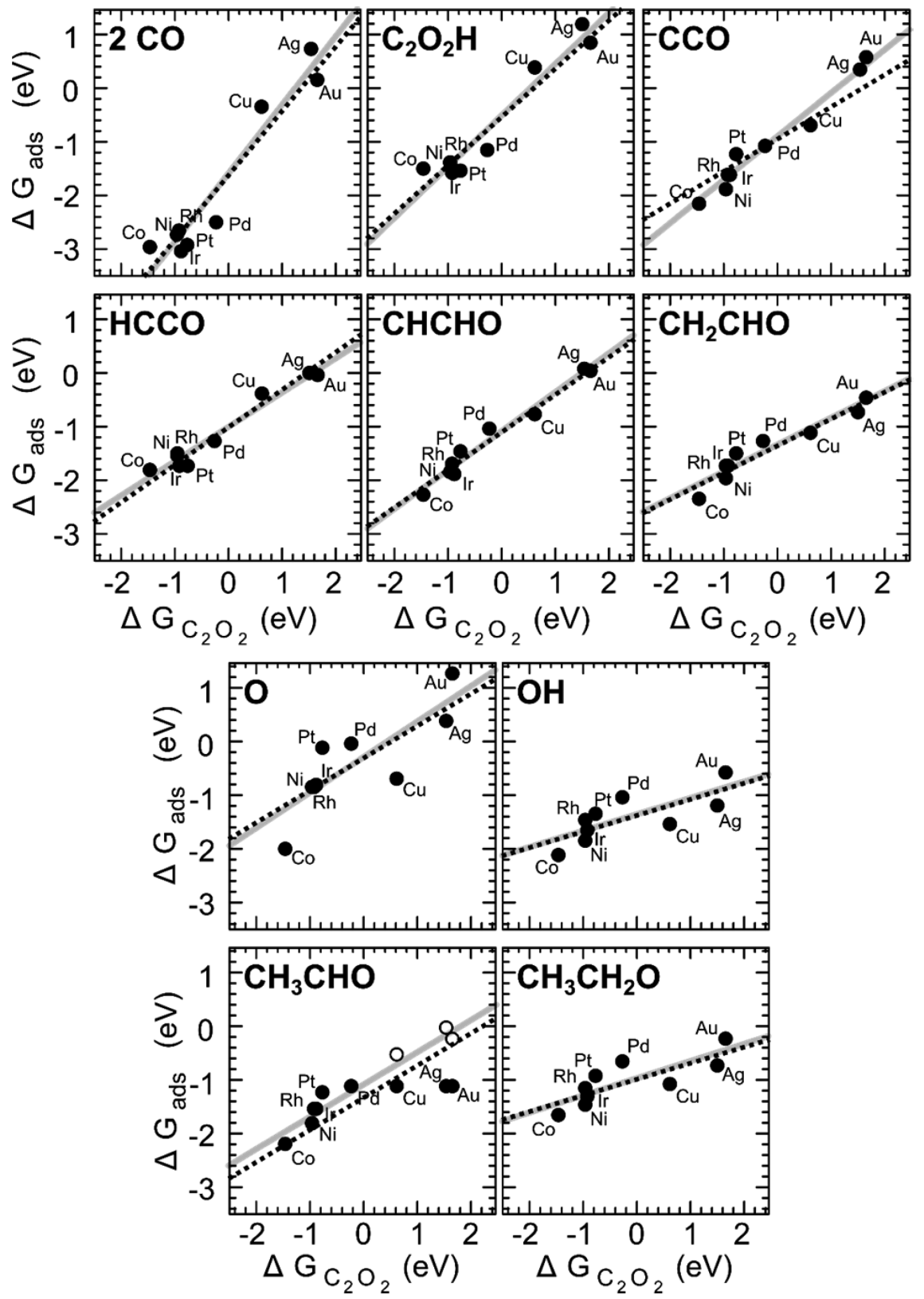

Figure 2. Adsorption energies $\Delta G_{\text {ads }}$ of all adsorbates in Figure 1 as a function of $\Delta G_{\mathrm{C}_{2} \mathrm{O}_{2}}$. Solid lines are the least-squares estimated scaling relations, the slopes and offsets of which appear in Table S.5; dotted lines represent slopes estimated using bond counts. For $\mathrm{CH}_{3} \mathrm{CHO}_{\text {, }}$ energies for adsorbates fixed onto metals are shown using empty circles.

second least negative limiting potential of $-1.13 \mathrm{~V}$ for $\mathrm{Ag}(100)$. Note that the earlier onset potential for ethylene production of $\mathrm{Cu}(100)$ compared to other late transition metals is also observed experimentally. ${ }^{5,6,14,18}$ However, the experimental onset potential on $\mathrm{Cu}(100)$ is around $-0.4 \mathrm{~V}$. The discrepancy arises because we do not implicitly ${ }^{17}$ or explicitly ${ }^{28}$ include cations in the calculations, which were recently shown to lower the calculated onset potential of ethylene from $-0.7--0.8 \mathrm{~V}$ to approximately $-0.3 \mathrm{~V}^{28}$ As cation effects have been observed on other metals, including them would likely shift all energy values downward, maintaining the activity trends. ${ }^{29}$ To investigate the effect of hydrogen coverage on our predictions, we coadsorbed $1 / 6$ and $1 / 3 \mathrm{ML} * \mathrm{H}$ with $\mathrm{C}_{2} \mathrm{O}_{2}$ and $\mathrm{COCOH}$ on $\mathrm{Cu}(100)$ and $\operatorname{Ir}(100)$, which shifted all binding energies in a consistent fashion, leaving the trends unchanged, as shown in Table S.7. However, hydrogen adsorption modulates $\mathrm{CO}$ adsorption and, ${ }^{30}$ hence, the probability of finding $2 * \mathrm{CO}$ close to each other, as required to produce $\mathrm{C}_{2}$ products. Summarizing, although hydrogen coadsorption has no significant effect on our activity trends, to obtain such trends we assumed that the ${ }^{*} \mathrm{CO}$ coverage on each metal is sufficiently high to allow for its dimerization, which depends on hydrogen coadsorption.

Because ${ }^{*} \mathrm{CH}_{3} \mathrm{CHO}$ is physisorbed on $\mathrm{Cu}(100), \mathrm{Ag}(100)$, and $\mathrm{Au}(100)$, these elements do not follow the scaling relation for other metals. Hence, the limiting potential for CORR to ethanol on $\operatorname{Ag}(100)$ is calculated to be $-0.46 \mathrm{~V}$. In other words, $\mathrm{Ag}(100)$ may selectively form ethanol instead of ethylene at relatively low overpotentials, although a detailed analysis including cation effects would be recommendable. This is an interesting result as ethanol has a higher market price than ethylene and is used as a high-energy-density fuel of easy 


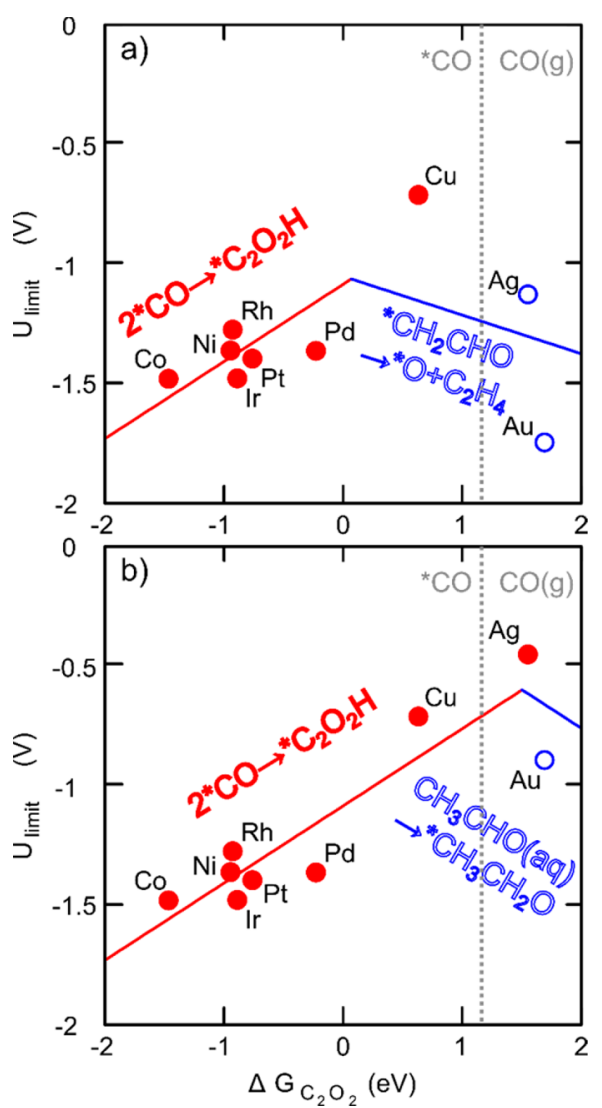

Figure 3. Volcano plots using $\Delta G_{\mathrm{C}_{2} \mathrm{O}_{2}}$ as a descriptor for ethylene (a) and ethanol (b) pathways on (100) facets. In each plot, strongbinding and weak-binding limiting steps are represented by red and blue; metals for which these steps are limiting are labeled by red and blue circles.

storage. ${ }^{3}$ This selectivity of $\mathrm{Ag}(100)$ toward ethanol was not observed by Hori et al. ${ }^{4}$ However, Hatsukade et al. observed small amounts of ethanol but no ethylene during $\mathrm{CO}_{2}$ reduction on silver electrodes. ${ }^{31}$ The discrepancy between our predicted low overpotential on $\operatorname{Ag}(100)$ compared to the significantly greater effective overpotential by Hatsukade et al. could be caused by our thermodynamic model disregarding kinetic barriers, the low $\mathrm{CO}$ equilibrium coverage expected on $\mathrm{Ag}$ (vertical dashed line in Figure 3), or alternative pathways and products not included in our model. It is also possible that ethanol be produced at low overpotentials only in quantities below detection limits. More promisingly, Clark et al. found that alloying $\mathrm{Ag}$ into $\mathrm{Cu}$ enhances CORR rates to $\mathrm{C}_{2}$ and tunes the selectivity toward ethanol and $\mathrm{C}_{2}$ (hydroxy)aldehydes. ${ }^{32}$ Combined with our observations, this strengthens the argument for investigating Ag-containing electrocatalysts for reducing $\mathrm{CO}_{2}$ and $\mathrm{CO}$ to $\mathrm{C}_{2}$ species.

The volcano plot for ethylene production in Figure 3a shows appreciable deviations for metals on the weak-binding side, in particular, $\mathrm{Cu}$ and $\mathrm{Au}$. These deviations are inherent to the model and caused by a low slope for $* \mathrm{CH}_{2} \mathrm{CHO} \rightarrow * \mathrm{O}+\mathrm{C}_{2} \mathrm{H}_{4}$ (Figure 1), which is justified by the small bond-count difference across the step. Conversely, for $2 * \mathrm{CO} \rightarrow * \mathrm{COCOH}$ and $* \mathrm{CH}_{3} \mathrm{CHO} \rightarrow * \mathrm{CH}_{3} \mathrm{CH}_{2} \mathrm{O}$, the bond-order differences are sufficiently large and the corresponding step potentials scale well enough with $\Delta G_{\mathrm{C}_{2} \mathrm{O}_{2}}$ to ensure the predictive power of these scaling relations. In the volcano plot for ethanol production (Figure $3 \mathrm{~b}$ ), the scaling relations and the actual data points exhibit a mean absolute error of $0.13 \mathrm{~V}$, aided by some greater bond-count difference across the weak-binding limit step.

We created two-dimensional volcano plots in Figure 4 for ethylene and ethanol production to evaluate whether a model
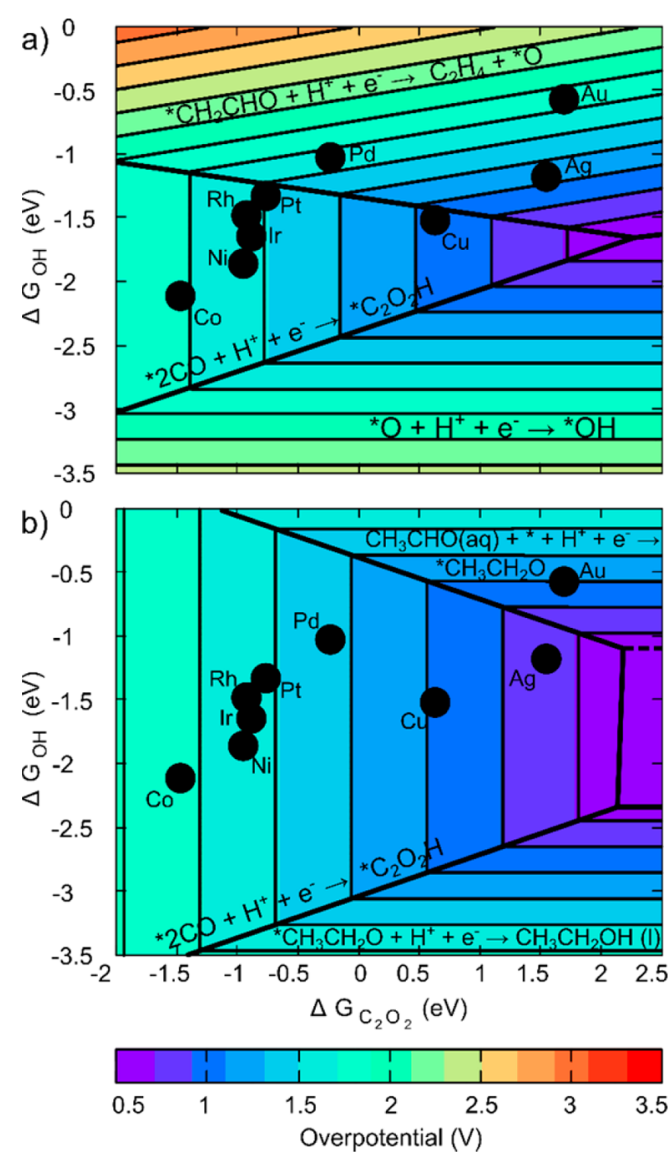

Figure 4. Two-dimensional volcano plots based on $\Delta G_{\mathrm{C}_{2} \mathrm{O}_{2}}$ and $\Delta G_{\mathrm{OH}}$ for ethylene (a) and ethanol (b) production.

explicitly accounting for both C-bound and O-bound adsorbates leads to higher accuracy and/or descriptiveness. We fitted step potentials across all metals to $\Delta G_{\mathrm{C}_{2} \mathrm{O}_{2}}, \Delta G_{\mathrm{OH}}$, or both, depending on the scalability of the adsorbates. Within these plots, additional steps are taken into account: $* \mathrm{O} \rightarrow$ $* \mathrm{OH}$ for ethylene production and $* \mathrm{CH}_{3} \mathrm{CH}_{2} \mathrm{O} \rightarrow \mathrm{CH}_{3} \mathrm{CH}_{2} \mathrm{OH}$ for ethanol production, both of which depend on $\Delta G_{\mathrm{OH}}$ only. The mean absolute deviation of the $2 \mathrm{D}$ models is $0.10 \mathrm{~V}$, which is slightly more accurate than the $1 \mathrm{D}$ plots in Figure 3. Thus, the $1 \mathrm{D}$ model seemingly suffices to rationalize the main trends.

In brief, we have provided in this Letter a simple computational model to explain trends in CORR to ethylene and ethanol among transition metals. The model shows that the bond-count difference is generally small between consecutive reaction intermediates. Hence, the slopes in the volcano plots are never steep, implying that large changes in adsorption energies of key intermediates are probably needed to observe sizable activity changes. The model confirms that $\mathrm{Cu}(100)$ is close to the volcano apex for ethylene production and, interestingly, shows that the onset potential for ethanol production on $\operatorname{Ag}(100)$ is rather low. This observation provides interesting inroads to further computational and experimental 
research to (i) improve the selectivity between $\mathrm{C}_{2}$ species, (ii) increase * $\mathrm{CO}$ coverage on $\mathrm{Ag}$, and (iii) clarify the role of $\mathrm{Ag}$ in $\mathrm{CuAg}$ and other Ag-based alloys.

\section{EXPERIMENTAL METHODS}

All calculations were performed using VASP and the PBE exchange-correlation functional. ${ }^{33,34}$ In the Supporting Information, we provide full details of the DFT calculations and the thermodynamic framework used in this Letter (see below a brief description of the Supporting Information).

\section{ASSOCIATED CONTENT}

\section{S Supporting Information}

The Supporting Information is available free of charge on the ACS Publications website at DOI: 10.1021/acsenergylett.8b00326.

Details of the DFT calculations, the computational hydrogen electrode, gas-phase and liquid-phase and solvation corrections, formation energies of species, adsorbate binding modes and average bond counts, adsorbate formation energy correlations and scaling relation parameters, $\mathrm{OH}$-based scaling relations and volcano plots, and hydrogen coadsorption effects (PDF)

\section{AUTHOR INFORMATION}

\section{Corresponding Author}

*E-mail: f.calle.vallejo@ub.edu.

\section{ORCID}

Marc T. M. Koper: 0000-0001-6777-4594

Federico Calle-Vallejo: 0000-0001-5147-8635

Notes

The authors declare no competing financial interest.

\section{ACKNOWLEDGMENTS}

F.C.-V. thanks the Spanish MEC for a Ramón y Cajal research contract (RYC-2015-18996). The use of supercomputing facilities at SURFsara was sponsored by NWO Physical Sciences, with financial support by NWO.

\section{REFERENCES}

(1) Lewis, N. S.; Nocera, D. G. Powering the Planet: Chemical Challenges in Solar Energy Utilization. Proc. Natl. Acad. Sci. U. S. A. 2006, 103, 15729-15735.

(2) McGlade, C.; Ekins, P. The Geographical Distribution of Fossil Fuels Unused when Limiting Global Warming to $2{ }^{\circ} \mathrm{C}$. Nature 2015, 517, 187-190.

(3) Schouten, K. J. P.; Calle-Vallejo, F.; Koper, M. T. M. A Step Closer to the Electrochemical Production of Liquid Fuels. Angew. Chem. Int. Ed. 2014, 53, 10858-10860.

(4) Hori, Y.; Takahashi, I.; Koga, O.; Hoshi, N. Selective Formation of $\mathrm{C}_{2}$ Compounds from Electrochemical Reduction of $\mathrm{CO}_{2}$ at a Series of Copper Single Crystal Electrodes. J. Phys. Chem. B 2002, 106, 1517.

(5) Schouten, K. J. P.; Pérez Gallent, E.; Koper, M. T. M. Structure Sensitivity of the Electrochemical Reduction of Carbon Monoxide on Copper Single Crystals. ACS Catal. 2013, 3, 1292-1295.

(6) Schouten, K. J. P.; Qin, Z.; Pérez Gallent, E.; Koper, M. T. M. Two Pathways for the Formation of Ethylene in CO Reduction on Single-Crystal Copper Electrodes. J. Am. Chem. Soc. 2012, 134, 98649867.
(7) Ma, X.; Li, Z.; Achenie, L. E. K.; Xin, H. Machine-LearningAugmented Chemisorption Model for $\mathrm{CO}_{2}$ Electroreduction Catalyst Screening. J. Phys. Chem. Lett. 2015, 6, 3528-3533.

(8) Li, H.; Li, Y.; Koper, M. T. M.; Calle-Vallejo, F. Bond-Making and Breaking between Carbon, Nitrogen, and Oxygen in Electrocatalysis. J. Am. Chem. Soc. 2014, 136, 15694-15701.

(9) Hori, Y.; Wakebe, H.; Tsukamoto, T.; Koga, O. Electrocatalytic Process of CO Selectivity in Electrochemical Reduction of $\mathrm{CO}_{2}$ at Metal Electrodes in Aqueous Media. Electrochim. Acta 1994, 39, $1833-1839$

(10) Gattrell, M.; Gupta, N.; Co, A. A Review of the Aqueous Electrochemical Reduction of $\mathrm{CO}_{2}$ to Hydrocarbons at Copper. J. Electroanal. Chem. 2006, 594, 1-19.

(11) Wuttig, A.; Liu, C.; Peng, Q.; Yaguchi, M.; Hendon, C. H.; Motobayashi, K.; Ye, S.; Osawa, M.; Surendranath, Y. Tracking a Common Surface-Bound Intermediate during $\mathrm{CO}_{2}$-to-Fuels Catalysis. ACS Cent. Sci. 2016, 2, 522-528.

(12) Schouten, K. J. P.; Kwon, Y.; van der Ham, C. J. M.; Qin, Z.; Koper, M. T. M. A New Mechanism for the Selectivity to $C_{1}$ and $C_{2}$ Species in the Electrochemical Reduction of Carbon Dioxide on Copper Electrodes. Chem. Sci. 2011, 2, 1902-1909.

(13) Calle-Vallejo, F.; Koper, M. T. M. Theoretical Considerations on the Electroreduction of $\mathrm{CO}$ to $\mathrm{C}_{2}$ Species on $\mathrm{Cu}(100)$ Electrodes. Angew. Chem. Int. Ed. 2013, 52, 7282-7285.

(14) Pérez-Gallent, E.; Figueiredo, M. C.; Calle-Vallejo, F.; Koper, M. T. M. Spectroscopic Observation of a Hydrogenated CO Dimer Intermediate During $\mathrm{CO}$ Reduction on $\mathrm{Cu}(100)$ Electrodes. Angew. Chem., Int. Ed. 2017, 56, 3621-3624.

(15) Montoya, J. H.; Shi, C.; Chan, K.; Nørskov, J. K. Theoretical Insights into a $\mathrm{CO}$ Dimerization Mechanism in $\mathrm{CO}_{2}$ Electroreduction. J. Phys. Chem. Lett. 2015, 6, 2032-2037.

(16) Garza, A. J.; Bell, A. T.; Head-Gordon, M. Mechanism of $\mathrm{CO}_{2}$ Reduction at Copper Surfaces: Pathways to $\mathrm{C}_{2}$ Products. ACS Catal. 2018, 8, 1490-1499.

(17) Jiang, K.; Sandberg, R. B.; Akey, A. J.; Liu, X.; Bell, D. C.; Nørskov, J. K.; Chan, K.; Wang, H. Metal Ion Cycling of Cu Foil for Selective C-C Coupling in Electrochemical $\mathrm{CO}_{2}$ Reduction. Nat. Catal. 2018, 1, 111-119.

(18) Ledezma-Yanez, I.; Gallent, E. P.; Koper, M. T. M.; CalleVallejo, F. Structure-Sensitive Electroreduction of Acetaldehyde to Ethanol on Copper and its Mechanistic Implications for $\mathrm{CO}$ and $\mathrm{CO}_{2}$ Reduction. Catal. Today 2016, 262, 90-94.

(19) Peterson, A. A.; Abild-Pedersen, F.; Studt, F.; Rossmeisl, J.; Nørskov, J. K. How Copper Catalyzes the Electroreduction of Carbon Dioxide into Hydrocarbon Fuels. Energy Environ. Sci. 2010, 3, 13111315.

(20) Peterson, A. A.; Nørskov, J. K. Activity Descriptors for $\mathrm{CO}_{2}$ Electroreduction to Methane on Transition-Metal Catalysts. J. Phys. Chem. Lett. 2012, 3, 251-258.

(21) Abild-Pedersen, F.; Greeley, J.; Studt, F.; Rossmeisl, J.; Munter, T. R.; Moses, P. G.; Skúlason, E.; Bligaard, T.; Nørskov, J. K. Scaling Properties of Adsorption Energies for Hydrogen-Containing Molecules on Transition-Metal Surfaces. Phys. Rev. Lett. 2007, 99, 016105.

(22) Calle-Vallejo, F.; Martínez, J. I.; García-Lastra, J. M.; Rossmeisl, J.; Koper, M. T. M. Physical and Chemical Nature of the Scaling Relations between Adsorption Energies of Atoms on Metal Surfaces. Phys. Rev. Lett. 2012, 108, 116103.

(23) Calle-Vallejo, F.; Loffreda, D.; Koper, M. T. M.; Sautet, P. Introducing Structural Sensitivity into Adsorption-Energy Scaling Relations by Means of Coordination Numbers. Nat. Chem. 2015, 7, 403-410.

(24) Calle-Vallejo, F.; Koper, M. T. M. Accounting for Bifurcating Pathways in the Screening for $\mathrm{CO}_{2}$ Reduction Catalysts. ACS Catal. 2017, 7, 7346-7351.

(25) Calle-Vallejo, F.; Krabbe, A.; García-Lastra, J. M. How Covalence Breaks Adsorption-Energy Scaling Relations and Solvation Restores Them. Chem. Sci. 2017, 8, 124-130.

(26) Su, H.-Y.; Sun, K.; Wang, W.-Q.; Zeng, Z.; Calle-Vallejo, F.; Li, W.-X. Establishing and Understanding Adsorption-Energy Scaling 
Relations with Negative Slopes. J. Phys. Chem. Lett. 2016, 7, 53025306.

(27) Peverati, R.; Truhlar, D. G. Quest for a Universal Density Functional: the Accuracy of Density Functionals Across a Broad Spectrum of Databases in Chemistry and Physics. Philos. Trans. R. Soc., A 2014, 372, 20120476.

(28) Pérez-Gallent, E.; Marcandalli, G.; Figueiredo, M. C.; CalleVallejo, F.; Koper, M. T. M. Structure- and Potential-Dependent Cation Effects on CO Reduction at Copper Single-Crystal Electrodes. J. Am. Chem. Soc. 2017, 139, 16412-16419.

(29) Chen, L. D.; Urushihara, M.; Chan, K.; Nørskov, J. K. Electric Field Effects in Electrochemical $\mathrm{CO}_{2}$ Reduction. ACS Catal. 2016, 6, $7133-7139$.

(30) Zhang, Y.-J.; Sethuraman, V.; Michalsky, R.; Peterson, A. A. Competition between $\mathrm{CO}_{2}$ Reduction and $\mathrm{H}_{2}$ Evolution on Transition-Metal Electrocatalysts. ACS Catal. 2014, 4, 3742-3748.

(31) Hatsukade, T.; Kuhl, K. P.; Cave, E. R.; Abram, D. N.; Jaramillo, T. F. Insights into the Electrocatalytic Reduction of $\mathrm{CO}_{2}$ on Metallic Silver Surfaces. Phys. Chem. Chem. Phys. 2014, 16, 13814-13819.

(32) Clark, E. L.; Hahn, C.; Jaramillo, T. F.; Bell, A. T. Electrochemical $\mathrm{CO}_{2}$ Reduction over Compressively Strained $\mathrm{CuAg}$ Surface Alloys with Enhanced Multi-Carbon Oxygenate Selectivity. J. Am. Chem. Soc. 2017, 139, 15848-15857.

(33) Kresse, G.; Furthmüller, J. Efficient Iterative Schemes for Ab Initio Total-Energy Calculations Using a Plane-Wave Basis Set. Phys. Rev. B: Condens. Matter Mater. Phys. 1996, 54, 11169-11186.

(34) Perdew, J. P.; Burke, K.; Ernzerhof, M. Generalized Gradient Approximation Made Simple. Phys. Rev. Lett. 1996, 77, 3865-3868. 